\title{
Review
}

\section{The new oral anticoagulants and the future of haemostasis laboratory testing}

\author{
Emmanuel J Favaloro ${ }^{1 *}$, Giuseppe Lippi² \\ 'Department of Haematology, Institute of Clinical Pathology and Medical Research (ICPMR), Westmead Hospital, NSW, Australia \\ ${ }^{2}$ Clinical Chemistry Laboratory, Department of Pathology and Laboratory Medicine, University Hospital of Parma, Italy
}

*Corresponding author: emmanuel.favaloro@swahs.health.nsw.gov.au

\begin{abstract}
The tests currently employed within most haemostasis laboratories to monitor anticoagulant therapy largely comprise the prothrombin time (PT)/ International Normalised Ratio (INR) and the activated partial thromboplastin time (APTT). These are respectively used to monitor Vitamin K antagonists (VKAs) such as warfarin, and unfractionated heparin. Additional tests that laboratories may also employ for assessing or monitoring unfractionated heparin include thrombin time (TT) and the anti-Xa assay, which can also be used to monitor low molecular weight heparin. Several new anti-thrombotic agents have recently emerged, or are in the final process of clinical evaluation. These novel drugs that include Dabigatran etexilate and Rivaroxaban would not theoretically require monitoring; however, testing is useful in specific situations. The tests currently used to monitor VKAs and heparin are typically either too sensitive or too insensitive to the new drugs to be used as 'typically performed in laboratories', and may thus require some methodological adjustments to increase or decrease their sensitivity. Alternately, different tests may be better employed in these assessments. Whatever the case, laboratories may soon be performing a reduced or possibly increased number of tests, the same kind of tests but perhaps differently, or conceivably different assay panels. Specific laboratory guidance on the choice of the appropriate test to be ordered according to the drug being administered, as well as on appropriate interpretation of test results, will also be necessary. The current report reviews the current state of play and provides a glimpse to the possible future of the coagulation laboratory.
\end{abstract}

Key words: haemostasis; coagulation; laboratory tests; anticoagulants; anti-thrombotics, Dabigatran, Rivaroxaban.

Accepted: September 07, 2012

\section{Background}

Anticoagulant therapy monitoring represents the main purpose of most routine coagulation laboratories, along with preoperative screening. Anticoagulants are alternatively referred to as 'antithrombotics', given their intended clinical therapeutic efficacy. The main current anticoagulant armamentarium comprises heparin and vitamin $\mathrm{K}$ antagonists (VKAs) (also known as coumarins) such as warfarin or acenocoumarol. The main new anticoagulant agents include, but do not exclusively comprise, Dabigatran etexilate, Rivaroxaban and Apixaban. VKAs and heparin are typically monitored because they exhibit a narrow therapeutic window, and largely unpredictable behavior in treated individuals. In contrast, the newer agents have been clinically developed and evaluated as requiring little to null laboratory monitoring. Laboratory testing of these agents will, however, be required in select cases, and laboratories should become proactive in recognizing the in-vitro behavior of these agents, developing appropriate strategies for any required testing, as well as establishing appropriate policies for post-test counseling on test results and expected outcomes.

\section{Haemostasis, thrombosis and anticoagulant/ antithrombotic therapy}

Haemostasis represents the mechanism whereby the body maintains circulatory flow. It can be represented by Vichow's triad or - more commonly as a balance of procoagulant and anticoagulant mechanisms or pathways, inclusive of fibrinolysis $(1,2)$. We have recently reviewed this in the context of the changing landscape of coagulation testing (3), and so shall only briefly reiterate the main aspects here. In brief, an injury to the vascular en- 
dothelium will initiate two major integrated 'procoagulant' pathways, termed primary and secondary haemostasis, which will lead to eventual plug formation to prevent excessive hemorrhage. The primary pathway involves activation of platelets, the recruitment of von Willebrand factor (VWF) to promote platelet attachment to the site of injury, and the engagement of secondary haemostasis through various procoagulant proteins including fibrinogen, and coagulation factors (F) V and VIII (1-3). Secondary haemostasis is also initiated directly by damage to the vasculature, primarily via the tissue factor pathway involving FVII, but also via the contact pathway, and as amplified by the primary pathway. In vitro, the tissue factor pathway and the contact pathway are respectively mirrored by the prothrombin time (PT) and activated partial thromboplastin time (APTT) (Figure 1).

Various natural anticoagulants (e.g., protein C $[P C]$, protein S [PS], antithrombin [AT]) act to moderate the secondary haemostasis pathway and prevent excessive procoagulant activity that may lead to thrombosis or vascular occlusion $(2,4)$. Thrombosis essentially represents a failure of the haemostatic balance, towards a state of 'procoagulation' (i.e., representing a comparative dominance of procoagulant mechanisms or a failure of natural anticoagulant mechanisms to effectively temper the procoagulant pathway) (2-5). Secondary haemostasis dysfunction leading to venous thrombosis is typically managed by anticoagulant therapy, classically comprising unfractionated heparin $(\mathrm{UH})$ or low molecular weight heparin (LMWH), and VKAs.

\section{Coagulation tests used to routinely monitor anticoagulant therapy}

For most haemostasis laboratories, the large bulk of routine coagulation tests performed comprise the PT/International Normalised Ratio (INR) for monitoring of VKAs, and within a hospital setting, the APTT for monitoring UH $(2,3,6-8)$. The INR represents a simple calculation as follows:

$$
\text { INR = (patient PT/MNPT) }{ }^{|S|},
$$

where the MNPT = mean normal PT, and ISI = international sensitivity index.
The reason that these two tests are used to respectively monitor VKAs and UF relate to linear sensitivity over the therapeutic interval (Table 1).

The Quick PT/INR is sensitive to the presence and activity of FII (prothrombin), FV, FVII, FX and fibrinogen (FI) (Figure 1). Thus, anticoagulant agents that affect the activity and/or level of these factors can influence this PT/INR, and by inference, the PT/INR can be used to monitor these agents if a dose response relationship can be established. The APTT is sensitive to the presence and activities of FII, FV, FVIII, FIX, FX, FXI, FXII and fibrinogen (FI) (Figure 1). Analogous to the PT/ INR, any anticoagulant agent that affects the activity and/or level of these factors can influence the APTT, and in turn, the APTT can be used to monitor these agents if a dose response relationship can be established. In practice, the PT/INR shows good linear sensitivity to VKAs over the therapeutic range, and the APTT shows linear sensitivity to UH over the conventional therapeutic range. In contrast, the PT/INR is less sensitive to $\mathrm{UH}$, and is actively made insensitive by addition of heparin neutralizers (e.g., heparinase or protamine), so that changes in the PT/INR during the transition of patients from UH to VKA therapy reflects the latter's effects only. Similarly, the APTT is less sensitive to VKAs than the PT/ INR.

These two basic coagulation tests are typically supplemented in many laboratories by fibrinogen assays, D-dimer tests, and occasionally thrombin time (TT) assays (Figure 1). Together, these five assays may be used to assess the haemostasis status in patients, including the potential for disseminated intravascular coagulation (9), as well in differential diagnosis strategies, or to assess for potential preanalytical issues (10). For example, the TT is very sensitive to UH (Figure 2), whereas fibrinogen assays tend to be less sensitive or are insensitive. Thus, the TT and fibrinogen testing may play a role in evaluating for a differential diagnosis of fibrinogen deficiency or heparin excess, which may be important in assessing for inappropriate sample collection, sample clotting or heparin contamination. Otherwise, the TT, fibrinogen and D-dimer tests do not normally play a big part 


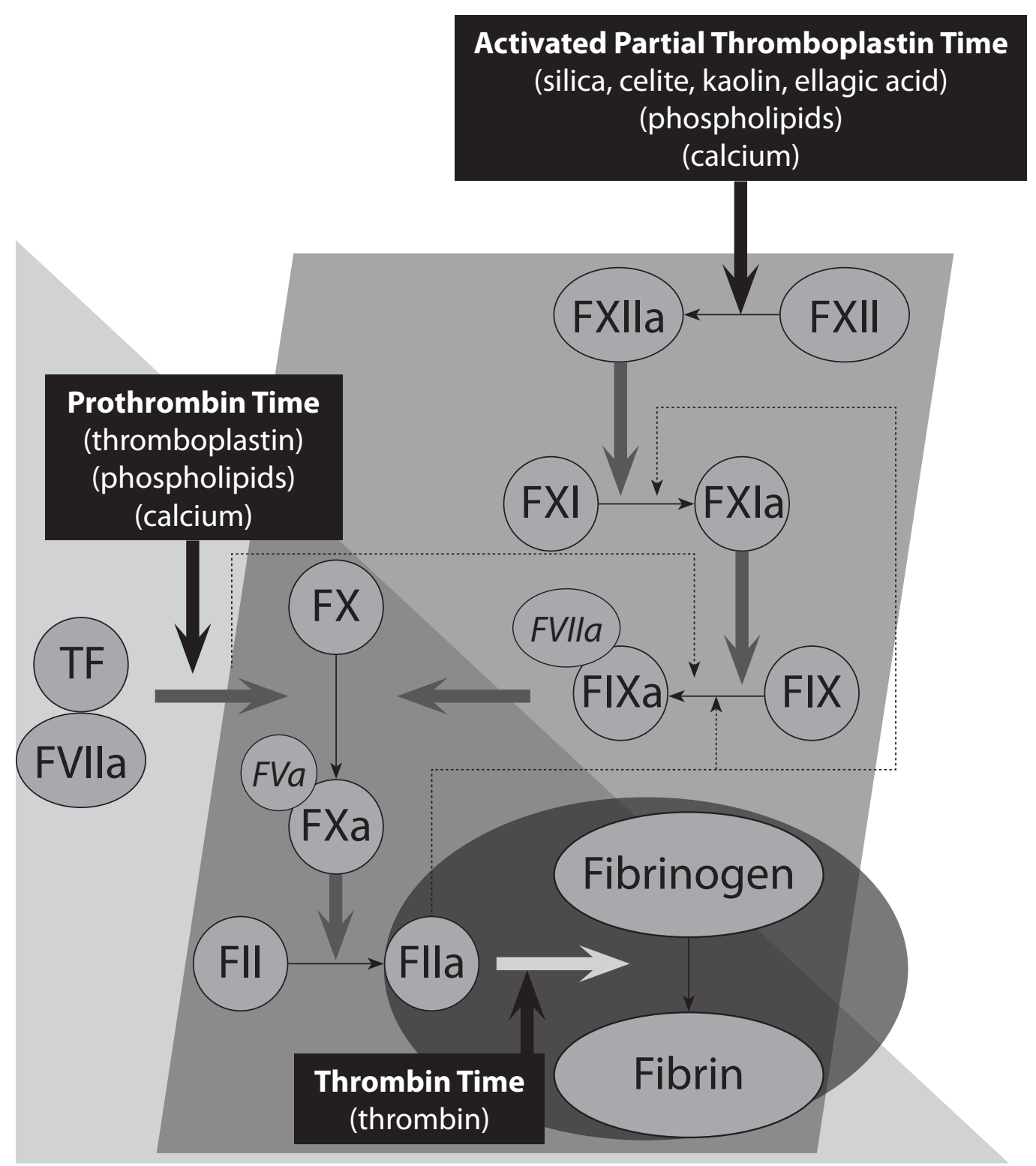

Figure 1. A simplified representation of the classical secondary pathway of coagulation as represented by the common in-vitro coagulation tests, namely the prothrombin time (PT), the activated partial thromboplastin time (APTT) and the thrombin time (TT).

in anticoagulant testing or antithrombotic therapy, except when the latter is used to assist decisions on the duration of anticoagulant therapy in patients with recent episodes of venous thrombosis.

\section{Non-routine 'anticoagulant monitoring' tests}

A small selection of additional tests are sometimes used to assess the anticoagulant status of patients undergoing anticoagulant therapy (3). The most commonly applied is the chromogenic anti-Xa assay (Figure 2), which is sensitive to the presence of
$\mathrm{UH}$, but which is most typically utilized - as required - to monitor LMWH (11).

\section{Anticoagulant therapy - the classical approach}

The post-thrombotic therapy is typically initiated using $\mathrm{UH}$, since this agent exerts an immediate anticoagulant effect (3). UH provides a varied clinical responsiveness in different people, only in part related to body mass index and adiposity, and hence requires monitoring to ensure that a sufficient anticoagulant effect is maintained, as well as to prevent administration of excessive anticoagulant 
that may lead to undesired bleeding. The narrow therapeutic window of anticoagulant effect is typically reflected by an APTT range of around 1.5-2.5x baseline values (11). UH is administered parenterally (i.e., intravenous sodium heparin), and although this is 'acceptable' for short-term hospital stays, it is uncomfortable for the patient. Other complications of UH therapy include the rare but potentially life-threatening condition known as heparin induced thrombocytopenia (HIT), which can also be associated with massive and lifethreatening thrombosis (HITT) (12-15).

Patients suffering thrombosis are thereby switched from UH to VKAs for long-term management. The normal post-thrombosis therapy lasts approximately 3-6 months, but in some cases can be extended (e.g., AT deficiency, or composite of identified risk factors) or indefinite (e.g. antiphospholipid syndrome (APS), atrial fibrillation (AF), prosthetic heart valves) $(16,17)$. VKAs are not immediate acting, taking several days to initiate effective anticoagulation (3). The dose-response is variable for several known and some unknown reasons, including compliance, pharmacogenetics, drug and food interactions $(18,19)$. VKAs are also characterized by a narrow therapeutic window, typically reflected by an INR around 2.0-3.0 or 2.5-3.5, depending on the clinical indication. The risk of bleeding might be worse than that with UH since the only effective therapeutic management is factor replacement therapy or administration of bypassing agents such as recombinant activated FVII or anti-inhibitor coagulant complex (20).

There is also the complicated issue of bridging from one agent (UH) to the other (VKAs), which requires additional clinical care and monitoring at this time. There are also clinical and laboratory costs associated with monitoring and testing. Moreover, there is much inter-laboratory variation in laboratory test practice and test results $(7,11,21)$, and variation also exists in terms of anticoagulant sensitivity for different PT and APTT reagents, thus casting some doubt on the actual clinical utility of some of the derived laboratory test results.

More recently, the use of UH is being significantly reduced and in some cases abandoned in several countries, because LMWH has taken its place also in the initial phase of venous thromboembolism (VTE) treatment. This later pharmacological agents consist of chains of polysaccharides obtained with different approach to fractionation or depolymerisation of polymeric heparin, which exhibit an average molecular weight of less than $8 \mathrm{kDa}$ and containing not less than $60 \%$ of chains with molecular weight lower than $8 \mathrm{kDa}$. LMWH provides some theoretical advantages over $\mathrm{UH}$ in terms of reduced need to monitor, and lower risk of complications such as HIT (11-15). LMWH is administered by subcutaneous injection, but different commercial products may differ substantially (22), and laboratory monitoring, if performed, is still plagued by substantial inter-laboratory variation (23).

\section{New anticoagulants}

The new and emerging oral anticoagulants are primarily direct inhibitors of either factor $\mathrm{Xa}$ or thrombin (FIla). These agents do not (in theory) require laboratory monitoring, since they have been largely developed and clinically investigated without laboratory testing $(3,24-28)$. The two agents most advanced in terms of global release and currently licensed clinical use are Dabigatran etexilate and Rivaroxaban, respectively reflecting anti-lla and anti-Xa agents. Another agent in an advanced stage is Apixaban, another anti-Xa agent. As with the development of most new anticoagulants, initial evaluation and clearance for clinical use tends to be in well-defined at-risk groups such as primary prophylaxis for VTE prevention in orthopaedic surgery, followed by medical applications of post VTE treatment and secondary prevention, and the 'holy grail' of anticoagulant drug treatment, namely AF and prevention of stroke or systemic thrombosis. Stroke prevention in AF is the underlying indication for approximately $50 \%$ of all patients treated with VKAs, and is thus a major target of the new anticoagulants, which is therefore expected to reflect the clinical indication that will mostly affect the role and organization of anticoagulant centers worldwide. Current approved indications for Dabigatran etexilate and Rivaroxaban are similar, and based on extensive trials showing either 

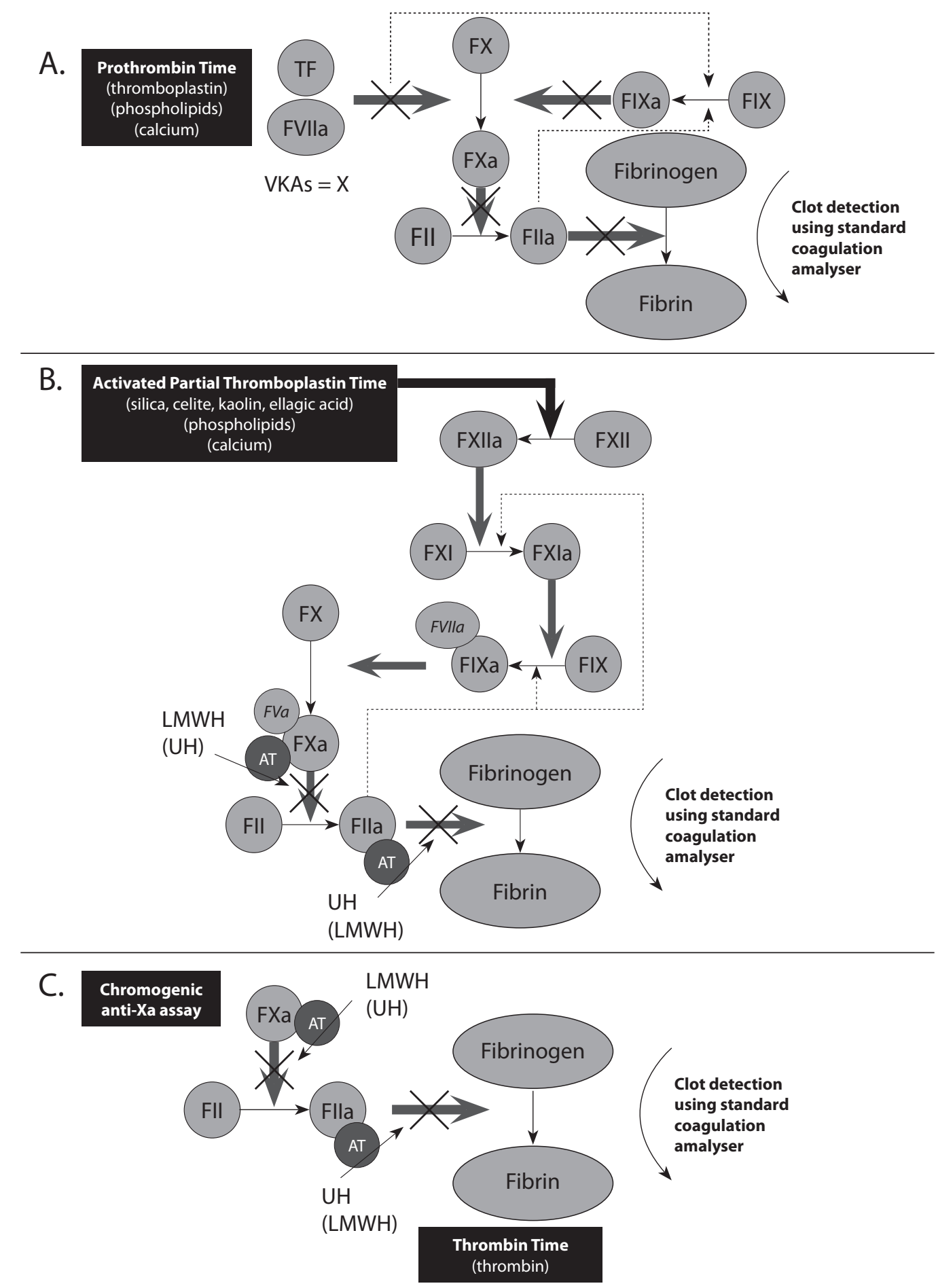

Figure 2. Control points for classical anticoagulants, and representation of monitoring by routine coagulation assays.

A. Control points for vitamin K antagonists (VKAs) are factors (F) II, VII, IX and X. Thus, any assay that acts as a measure of the activity of one or more of these factors can potentially act as a tool to assess drug effects. The prothrombin time (PT) adjusted to an International Normalised Ratio (INR) is determined to offer the best practical solution in this regard.

B \& C. Control points for heparin, which exerts its effects via antithrombin (AT). Low molecular weight heparins (LMWH; e.g., Clexane and Fragmin) express primarily anti-Xa activity. Unfractionated heparin (UH) expresses primarily anti-thrombin (anti-Ila) activity. To a lesser extent, LMWH also expresses some anti-thrombin activity and UH also expresses some anti-Xa activity. The assays judged to best measure the relevant activity and drug effects in this system are the APTT and anti-Xa assays. The APTT is sensitive to UH and is thus used to monitor UH therapy. The APTT is relatively insensitive to LMWH, and thus this can only be monitored by the anti-Xa assay. The TT is also sensitive to UH, but not LMWH. 
non-inferiority or superiority to alternate therapies, typically the LMWH enoxaparin, $40 \mathrm{mg}$ once daily for prevention of VTE or VKA for prevention of systemic embolism in patients with AF.

\section{No monitoring required?}

Although most of these novel anticoagulant agents have been developed on the premise of not requiring any monitoring, the reality is proving to be quite different. Overall, there will be many occasions in which clinicians will like to know whether or not an anticoagulant effect is evident:

1) an unconscious patient admitted to hospital with trauma, bleeding or for urgent surgery the presence of active anticoagulant may influence management or increase the risk of perioperative bleeding;

2) a case of attempted suicide - has an overdose of anticoagulant drug been taken?;

3) a case of thrombosis or hemorrhage while on anticoagulant therapy to help assess compliance or therapy failure;

4) when bridging from one anticoagulant to another;

5) for assessing compliance in select individuals;

6) in patients with metabolic abnormalities (e.g., those with impaired renal or liver function) or extreme body size; or

7) to establish whether co-medication effects are affecting drug efficacy.

As specifically regards assessing compliance, the half life of most of the new oral anticoagulants is comprised between 10 and 14 hours, with anticoagulant effects spanning from 24 to 36 hours. As such, compliance may be virtually assessed only within $\sim 12$ hours from ingestion of the last tablet. It is also noteworthy that test results may be highly different when the blood sample is collected 2 hours after the last tablet intake (which roughly corresponds to the peak) as compared with 12 or 24 hours afterwards in cases of twice or once daily intake, respectively.

However, as these agents have been developed and assessed in clinical trials without any monitor- ing of anticoagulant effect, there are no standardized or well established tests for their effective assessment. As the new agents are either directed against Flla or FXa, then tests that are sensitive to these agents are those most likely to be used for their laboratory assessment.

\section{Dabigatran etexilate}

For Dabigatran, the standard PT assay is too insensitive, and the APTT, although somewhat sensitive (increases in non-linear fashion), may underestimate high levels $(24,29-32)$ (Table 1). This may pose a significant problem in terms of over-dosing risk assessment. As Dabigatran is an anti-thrombin agent, it has no effect on the anti-Xa assay. The ecarin clotting time (ECT) and TT are both sensitive to Dabigatran (Figure 3), but the standard TT is oversensitive. Thus, the main contenders for routine use appear to be either the ECT or a modified (e.g., 'diluted') TT, although a combination of assays may provide a better clue for the possible scenario of Dabigatran overdosing. Interestingly, the manufacturer of Dabigatran (Boehringer Ingelheim) has recently published in-vitro studies (33) using a commercial dilute TT method called HEMOCLOT (HYPHEN BioMed, France), and thus indicating that the manufacturer itself recognizes the value of assessing for drug levels in select circumstances and specific clinical conditions. It is also interesting that Boehringer Ingelheim now appear to be favoring the HEMOCLOT assay for this purpose. Although it is possible to use inhouse derived (e.g., 'dilute') TT method for assessing Dabigatran, there is merit in having a standardized commercial assay to improve cross-laboratory concordance and harmonization.

The ECT, however, remains in contention. The ECT is a meizothrombin generation test that can generally be used to measure the activity of direct thrombin inhibitors (Figure 3). Ecarin is a highly purified metalloprotease isolated from the venom of the saw-scaled viper Echis carinatus and a specific activator of prothrombin (34). However, to date, there is no standard ECT methodology available. An alternative to the ECT is a commercially available echarin based chromogenic assay. 
TABLE 1. A summary of laboratory tests used in monitoring/testing anticoagulant therapy/activity.

\begin{tabular}{|c|c|c|c|c|c|}
\hline Test & $\begin{array}{l}\text { Sensitive } \\
\text { to } \\
\text { deficiency/ } \\
\text { activity of } \\
\text { factors: }\end{array}$ & VKAs & Heparin & $\begin{array}{c}\text { Dabigatran } \\
\text { etexilate }\end{array}$ & Rivaroxaban \\
\hline $\begin{array}{l}\text { Prothrombin } \\
\text { time (PT) / } \\
\text { International } \\
\text { Normalised } \\
\text { Ratio (INR) }\end{array}$ & I, II, V, VII, X & $\begin{array}{l}\text { Sensitive to, and used } \\
\text { for monitoring of, VKAs } \\
\text { (or coumarins such as } \\
\text { warfarin). VKAs affect } \\
\text { FII, FVII and FX in this } \\
\text { coagulation pathway. This } \\
\text { reflects } 3 / 5 \text { factors from } \\
\text { this pathway, including } \\
\text { FVII (which has the } \\
\text { shortest half life). Thus, } \\
\text { the PT/INR shows best } \\
\text { sensitivity to VKAs as well } \\
\text { as changes in therapy } \\
\text { and potential influences } \\
\text { of complicating } \\
\text { interactions. }\end{array}$ & Generally insensitive. & Too insensitive. & $\begin{array}{l}\text { May show some } \\
\text { linearity with } \\
\text { select (but not } \\
\text { all) reagents, } \\
\text { and low dose } \\
\text { response may } \\
\text { be poor. INR } \\
\text { system not } \\
\text { recommended } \\
\text { for use. }\end{array}$ \\
\hline $\begin{array}{l}\text { Activated Partial } \\
\text { Thromboplastin } \\
\text { Time (APTT). }\end{array}$ & $\begin{array}{l}\text { I, II, V, VIII, } \\
\text { IX, X, XI, XII }\end{array}$ & $\begin{array}{l}\text { Somewhat sensitive } \\
\text { (increases in non-linear } \\
\text { fashion). }\end{array}$ & $\begin{array}{l}\text { Most APTT reagents show } \\
\text { linear sensitivity over the } \\
\text { therapeutic range to UH, } \\
\text { which can also be assessed } \\
\text { against an anti-Xa assay. } \\
\text { Some minor sensitivity to } \\
\text { LMWH, but insufficient for } \\
\text { monitoring purposes. }\end{array}$ & $\begin{array}{l}\text { Somewhat } \\
\text { sensitive } \\
\text { (increases in } \\
\text { non-linear } \\
\text { fashion), but may } \\
\text { underestimate } \\
\text { high levels. }\end{array}$ & $\begin{array}{l}\text { APTT is } \\
\text { prolonged dose } \\
\text { dependently, } \\
\text { but is less } \\
\text { sensitive than } \\
\text { the PT. }\end{array}$ \\
\hline $\begin{array}{l}\text { Thrombin time } \\
\text { (TT) }\end{array}$ & I (Ila) & Insensitive & $\begin{array}{l}\text { TTs tend to be too sensitive } \\
\text { to UH, and thus are useful } \\
\text { only to show the presence } \\
\text { or absence of UH (i.e., not } \\
\text { useful for monitoring of } \\
\text { UH, since poor linearity in } \\
\text { therapeutic range). Fairly } \\
\text { insensitive to LMWH. }\end{array}$ & $\begin{array}{l}\text { Standard TT is } \\
\text { oversensitive; } \\
\text { dilute TT or } \\
\text { commercial } \\
\text { method } \\
\text { (HEMOCLOT) } \\
\text { appear suitable } \\
\text { options }\end{array}$ & Insensitive. \\
\hline $\begin{array}{l}\text { Chromogenic } \\
\text { anti-Xa assay }\end{array}$ & X (activated) & Insensitive & $\begin{array}{l}\text { Can be used to monitor } \\
\text { both LMWH and UH. Not } \\
\text { performed in routine } \\
\text { coagulation laboratories. } \\
\text { Limited clinical data } \\
\text { related to utility in } \\
\text { individual patients. Poor } \\
\text { reproducibility between } \\
\text { laboratories. }\end{array}$ & Insensitive & $\begin{array}{l}\text { Standard assay } \\
\text { as used for } \\
\text { monitoring } \\
\text { heparin is } \\
\text { too sensitive. } \\
\text { Modified } \\
\text { anti-Xa assay } \\
\text { appears } \\
\text { suitable. }\end{array}$ \\
\hline $\begin{array}{l}\text { Ecarin Clotting } \\
\text { Time (ECT) }\end{array}$ & II (activated) & Insensitive & Variably sensitive & $\begin{array}{l}\text { Sensitive. } \\
\text { Appears } \\
\text { reasonable } \\
\text { option. }\end{array}$ & Insensitive \\
\hline dRVVT assay & $\mathrm{I}, \mathrm{II}, \mathrm{V}, \mathrm{X}$ & Sensitive & $\begin{array}{l}\text { Sensitive to UH if reagent } \\
\text { does not contain a heparin } \\
\text { neutralizer. Insensitive if } \\
\text { reagent contains a heparin } \\
\text { neutralizer. }\end{array}$ & $\begin{array}{l}\text { Sensitive. } \\
\text { Requires more } \\
\text { extensive } \\
\text { evaluation. }\end{array}$ & $\begin{array}{l}\text { Sensitive. } \\
\text { Requires more } \\
\text { extensive } \\
\text { evaluation. }\end{array}$ \\
\hline
\end{tabular}


A.

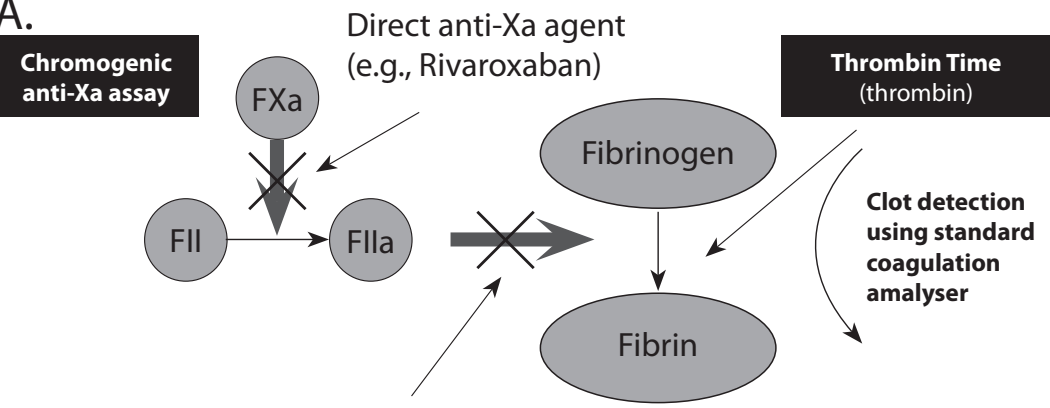

Direct antithrombin agent (e.g., Dabigatran)

B.

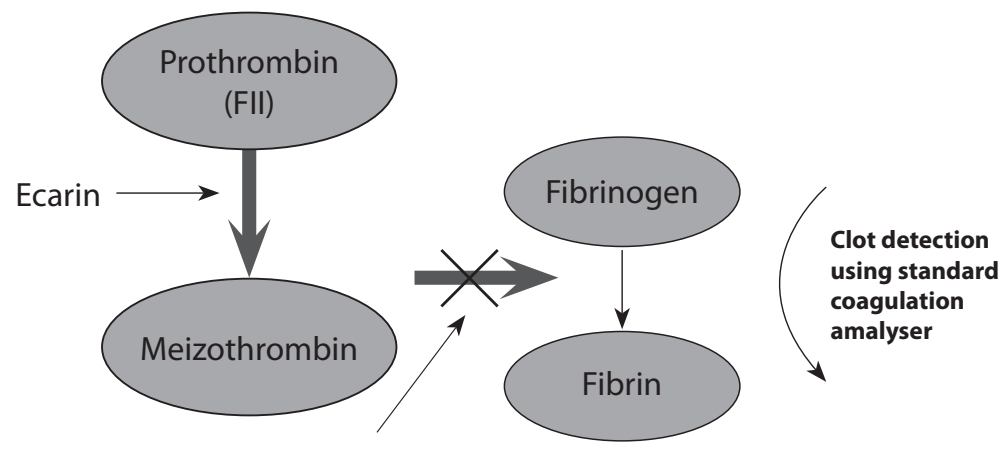

Direct antithrombin agent (e.g., Dabigatran)

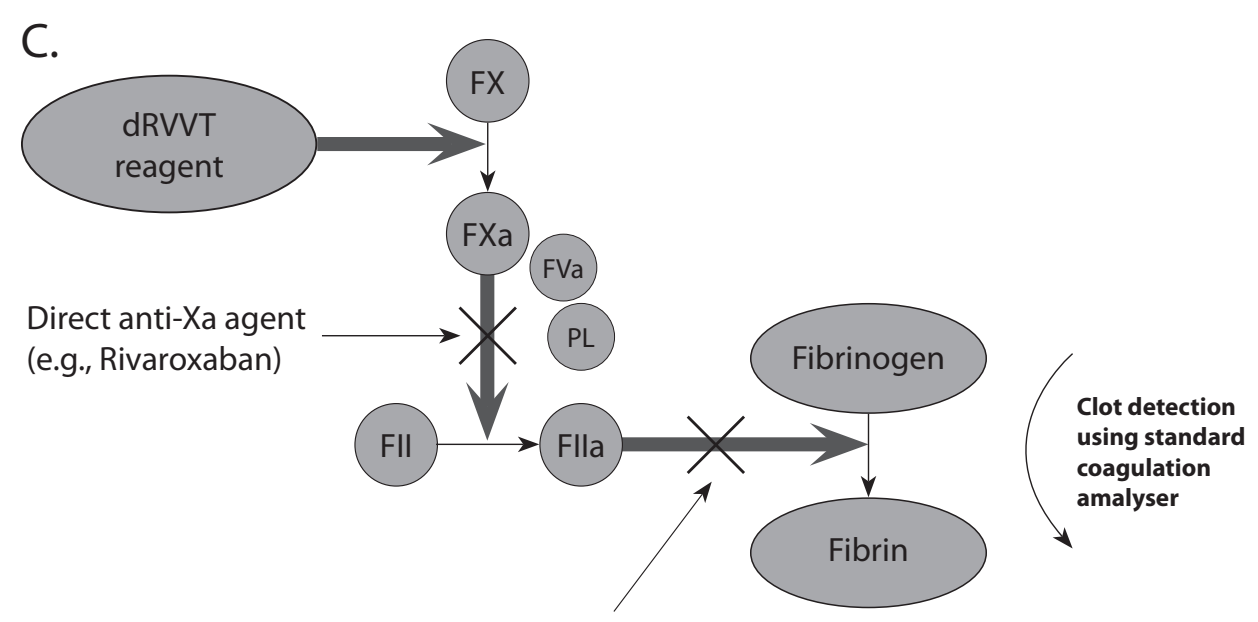

Direct antithrombin agent

(e.g., Dabigatran)

FIGURE 3. Control points for new agents directed against thrombin (Flla) and factor (F) Xa, and representation of testing by specific coagulation assays. These agents do not require antithrombin (AT) in order to exert their anticoagulant effects.

A. Similar to LMWH, Rivaroxaban has anti-Xa activity and can therefore be monitored by an anti-Xa assay. Note, however, that the standard assay used to monitor LMWH is too sensitive to Rivaroxaban, and needs to be modified. Similar to UH, Dabigatran has antiIla activity, and thus the TT is sensitive to Dabigatran. Note, however, that the standard TT assay is too sensitive to Dabigatran, and needs to be modified.

B. A representation of the ecarin clotting assay, likely to emerge as a useful test for the assessment of anti-thrombin (Flla) agents such as Dabigatran. The assay is sensitive to the effects of such agents, is simple to perform, able to be adapted to and automated on most routine laboratory coagulation instruments, and also likely to be capable of standardisation. A chromogenic version is also available. C. A representation of the (dilute) Russell Viper Venom Time (dRVVT) assay, currently under-investigated for any potential utility in assessing the effects of Dabigatran and Rivaroxaban, but which may emerge as a useful test for such purpose. 


\section{Rivaroxaban}

Although the PT shows some linearity against Rivaroxaban concentrations with some (but not all) reagents (24,35-37), the INR system, developed for VKA therapy, is not recommended for assessing $\mathrm{Ri}$ varoxaban activity, as ISI and MNPT values developed for VKA use may not apply to this agent (Table 1). As Rivaroxaban is directed against FXa, it has no effect on the ECT or the TT. The APTT is also prolonged by Rivaroxaban in a dose dependent manner, and anti-FXa activity is also influenced by Rivaroxaban (35-37). However, the standard antiXa assay, as used for monitoring heparin, is too sensitive to Rivaroxaban, and thus a modified (or 'diluted') assay is required for use in Rivaroxaban testing. Nevertheless, the anti-Xa assay remains the most likely contender for assessment of Rivaroxaban activity (Figure 3), although PT and APTT assays, perhaps in modified form, may also emerge as useful tests for this purpose.

\section{Can we use other laboratory tests to monitor these agents?}

Other tests evaluated for sensitivity to these two agents, as well as many other agents in development, include the dilute PT, the reptilase time, thrombin generation, thromboelastography, HepTest (a clot based anti-Xa assay), the 'prothrombinase induced clotting time' (PICT), the dilute Russell Viper Venom Time assay, and a chromogenic anti-Flla assay (3,24,29-32,35-37). The behaviour of some of these tests was as expected, and on other occasions appears paradoxical (e.g., low doses of Rivaroxaban showed an unexpected shortening of the PICT), thus suggesting that some test refinements would be necessary before such tests could be utilised for assessment of anticoagulant activity with these agents.

Unlike the standard routine assays, some of these tests are unavailable (and likely to remain as such) to most laboratories, and therefore unlikely to be initiated for routine assessment of these agents. For example, the thrombin generation assay is affected by both Dabigatran and Rivaroxaban (24), and may be useful not only for detecting over-coagulation, but also for monitoring anticoagulation reversal (38). However, it is unlikely that many laboratories could implement the thrombin generation assay in practice, as it cannot be performed using standard coagulation equipment.

One assay that appears to have been under-investigated in this arena is the dilute Russell's viper venom time (dRVVT) assay, which is most commonly employed as the major test in the investigation of lupus anticoagulant (LA) $(39,40)$. The dRVVT is sensitive to effects of both FX/FXa and FII/Flla, and thus represents an assay that could hold utility for assessing the effects of both Dabigatran and Rivaroxaban. Indeed, preliminary testing has shown the dRVVT to be more sensitive to the activities of these agents than some other tests previously investigated (Figure 4). Given that this test is commonly utilized by laboratories for LA investigation $(39,40)$, it should be more fully investigated for potential utility in other scenarios such as assessing the new anticoagulants.

\section{Standards}

Although there are several tests that in theory could assess whether or not there is anticoagulant activity associated with many of the new anticoagulants, standards for assay calibration have only recently become available, hampering progress with in-vitro testing and standardisation. In theory, Rivaroxaban obtained as a pharmacy supply could be used as a laboratory calibrator standard (i.e., by spiking plasma samples), just like heparin obtained from a pharmacy supply is typically used as a standard/calibrator for anti-Xa testing in heparin monitoring applications. On the other hand, Dabigaran etexilate is a pro-drug, requiring in vivo conversion to an active compound for its activity, further complicating provision of an in vitro standard by which to effectively reflect its biological activity in vivo. That is, Dabigaran etexilate itself cannot be used as a standard (i.e., by spiking plasma samples) in a laboratory testing process attempting to assess its ex-vivo activity. Moreover, given the clinical testing and subsequent marketing of these agents as 'not requiring monitoring', there has been resistance from the drug manufacturers to provide active drugs that could be used by laboratory as assay standards, presumably since this 
A.

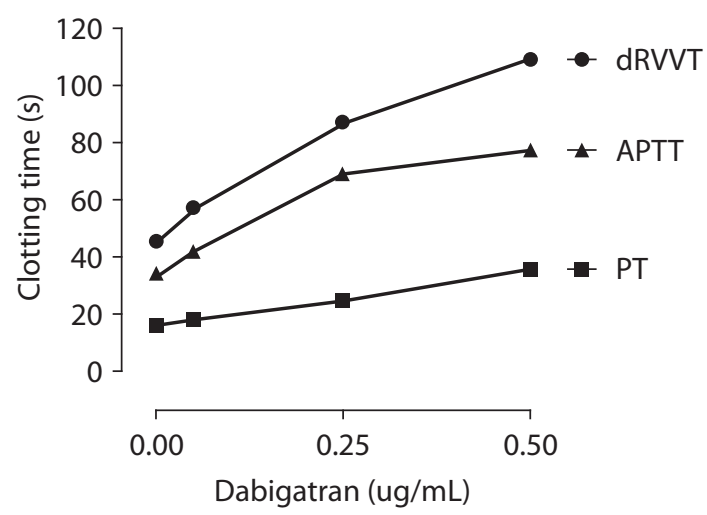

B.

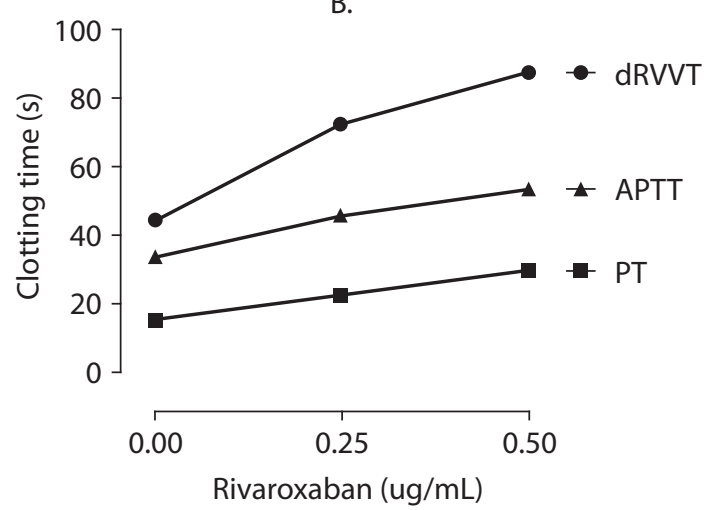

C.

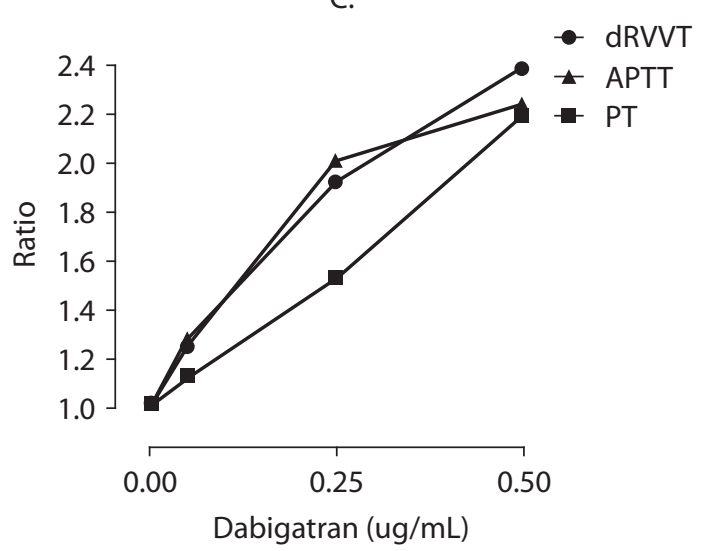

D.

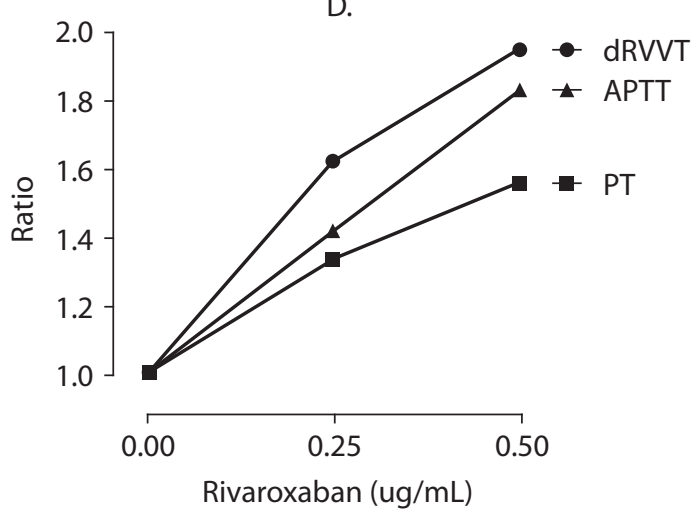

Figure 4. Comparative sensitivities of PT, APTT and dRVVT assays to Dabigatran and Rivaroxaban using data derived from the Westmead laboratory. Reagents were respectively: Thromborel S (Siemens, Sydney Australia), TriniClot APTT HS (Tcoag, Bray, Ireland), STA $^{\oplus}$-Staclot ${ }^{\circledR}$ DRVV Confirm reagent (Stago, Sydney Australia). Dabigatran and Rivaroxaban plasma standards as tested were from Hyphen BioMed (purchased from Haematex, Sydney Australia). All testing was performed on a STA-R Evolution instrument (Stago, Sydney Australia).

A. Dabigatran concentration vs. clotting times.

B. Rivaroxaban concentration vs. clotting times.

C. Dabigatran concentration vs. clotting ratio (clotting time/baseline clotting time).

D. Rivaroxaban concentration vs. clotting ratio (clotting time/baseline clotting time).

Note the comparative dRVVT findings in each case. In particular, the dRVVT was sensitive to both anticoagulants and clotting ratios for dRVVT were reasonably linear and similar for Dabigatran and Rivaroxaban over the tested concentrations.

would reflect a position at odds with their drug 'no-monitoring required' marketing strategy. However, this situation may be set to change, given the recent interesting and apparent shift from Boehringer Ingelheim, the manufacturer of Dabigaran etexilate (33).

\section{Future perspectives}

The development of new anticoagulants that in theory do not require monitoring would predict the demise of the current anticoagulants (i.e., hep- arin and VKAs), and thus the potential 'doom' of routine coagulation tests, given that these tests are primarily used for this purpose. Indeed, even should 'occasional testing' be required for the new anticoagulants, the standard tests (PT/INR, APTT, TT) as currently performed in laboratories would not be suitable, due to poor sensitivity, over sensitivity, and/or the lack of an optimal dose-response relationship. Since these routine tests reflect the 'core business' of haemostasis testing, the obvious question arises of whether this marks the inevitable doom of routine haemostasis laboratories. 
Our advice is don't close up shop just yet. Despite the optimistic predictions about the superior clinical utility of the new anticoagulants as antithrombotic agents, the existing anticoagulants (i.e., VKAs, heparin/heparinoids) are likely to remain in use for some time to come $(1,3,28)$. The new anticoagulants appear from clinical trials to have a favorable safety profile. Nevertheless, the high specificity (i.e., either anti-Ila or anti-Xa) of these agents would indicate limited utility for some applications. For example, these agents may not be able to replace the conventional anticoagulant drugs in polytherapeutic approaches (e.g., management of coronary syndromes, thrombotic stroke, and malignancy-associated thrombosis). The current lack of reversal or antidote for most agents also means general unsuitability for some 'during surgery' indications such as on-pump coronary bypass, where heparin and anti-aggregant agents are still the cornerstone of therapy. Cost is another issue. Heparin and VKAs are cheap drugs compared to the new anticoagulants. Patients in developing countries as well as sections of the population in developed countries may remain on VKA therapy simply because of affordability, which is also linked to compliance. With the expense of the new drugs, some patients are tempted to skip or reduce doses, with potentially devastating consequences, and so may be more safely managed on VKAs.

Drug evaluation studies are also performed with selected patient cohorts, in many respects 'ideal' patients, with many other subjects ('non-ideal' patients) excluded for various reasons $(41,42)$. Typically excluded are those patients with renal and liver dysfunctions, pregnant women, pediatric populations, individuals at extremes of body weight and individuals with complex disease and multiple morbidities. Notably, there was a high exclusion rate in the clinical trials evaluating both Dabigatran and Rivaroxaban. However, when these drugs are eventually released and approved for selective indications in the real world, 'non-ideal' patients, including those excluded by clinical trial criteria, will also need to be managed by anticoagulation therapy. There has also been much recent publicity about adverse events including death whilst on the new agents, and possibly related to selection of inappropriate patients to treat (e.g., renal dysfunction). Naturally, the old anticoagulants are also not without significant risk of bleeding or other serious adverse outcomes, as previously highlighted. The future anticoagulation of patients with complex diseases is again worth raising here. Clinical trials that aim to include such patients will be delayed by drug developers, given the possibility of adverse comparative findings against the classical agents, and thus potential negative influence on approvals for other indications.

Another interesting consideration is the potential role of anticoagulant therapy in modulating cancer spread, given the reported bidirectional relationship of cancer and haemostasis (43). At the current time, heparins - especially LMWH - appear to provide the best potential option in this regard, believed due to their anti-thrombin activity which targets the protease-activated receptor (PAR) pathway, and thus, the potential role of the new anticoagulants in this area of treatment remains an academic point.

\section{Conclusions}

In summary, the new oral anticoagulants cannot entirely replace the classical anticoagulants (heparin and VKAs). Therefore, these will remain key anticoagulants for the foreseeable future. As these will still require laboratory monitoring, the routine coagulation tests (PT/INR and APTT) will similarly remain a part of this foreseeable future as well. These tests will also still have value in assessing for haemostasis related defects, potentially related to both bleeding and thrombosis $(1,6,8,9,44,45)$. Moreover, renal failure, liver dysfunction, extremes of body weight and even genetic polymorphisms may influence adsorption, clearance, metabolism and excretion of some of the new and emerging anticoagulants. Combined with the current lack of ideal anticoagulant antidotes, the need or clinical desire for laboratory testing (in lieu of 'monitoring') of the new anticoagulants is predictable. Additional reasons for laboratory testing include to assess compliance or therapy failure (unexpected thrombosis or bleeding), to establish whether co-medication effects may be affecting drug efficacy, when bridging from one anticoagulant to another, and in unconscious patients (e.g., trauma) undergoing 
surgery. Accordingly, 'routine' laboratory testing of the new anticoagulants will also develop over time. Evaluations into which tests might be useful for monitoring these have started, with the diluted TT or ECT, and the chromogenic anti-Xa assays currently emerging as clear leaders for potential clinical utility of Dabigatran and Rivaroxaban testing respectively. However, the 'common' tests, including the PT and APTT, might be found to be suitable in time, albeit in modified form (e.g., dilute PT). A chromogenic anti-lla or chromogenic ecarin assay would also be feasible contenders for assessment of Dabigatran, particularly for those laboratories already running a chromogenic anti-Xa assay. Finally, the dRVVT remains under-investigated but represents another potential opportunity, in theory permitting dual assessment of both Dabigatran and Rivaroxaban. Nevertheless, performance of any of these assays for assessment of the anticoagulant effects of Dabigatran and Rivaroxaban in the absence of adequate standards and adequate test standardization would suggest current limited or questionable clinical utility. There will also be a clear need to develop appropriate quality control and external quality assurance processes for these tests when used in these settings, which is anything but ancillary (46). Specific laboratory coun-

\section{References}

1. Favaloro EJ, Lippi G. Coagulation Update: What's new in hemostasis testing? Thromb Res 2011;127 Suppl 2:S13-6.

2. Lippi G, Favaloro EJ, Franchini M, Guidi GC. Milestones and perspectives in coagulation and hemostasis. Semin Thromb Hemost 2009;35:9-22.

3. Favaloro EJ, Lippi G, Koutts J. Laboratory testing of anticoagulants - the present and the future. Pathology 2011;43:682-92.

4. Tufano A, Coppola A, Cerbone AM, Ruosi C, Franchini M. Preventing postsurgical venous thromboembolism: pharmacological approaches. Semin Thromb Hemost 2011;37:252-66.

5. Lippi G, Franchini M. Pathogenesis of venous thromboembolism: when the cup runneth over. Semin Thromb Hemost 2008;34:747-61.

6. Favaloro EJ, Adcock DM. Standardization of the INR: how good is your laboratory's INR and can it be improved? Semin Thromb Hemost 2008;34:593-603.

7. Favaloro EJ, McVicker W, Hamdam S, Hocker N. Improving the harmonisation of the International Normalized seling on the most appropriate test to be ordered according to the drug being administered, as well as on the best way to interpret test results will also be necessary, at least for the initial period of utilization of these novel anticoagulant agents $(47,48)$.

In conclusion, the 'imminent demise' of the routine coagulation laboratory, and of the PT/INR and APTT, appears a little premature. The future landscape will include a more varied test menu, tailored towards monitoring or testing of a broader group of anticoagulants, including but not limited to heparin, VKAs, Dabigatran and Rivaroxaban. The classical five test (i.e., PT/INR, APTT, TT, Fibrinogen and D-dimer) panels used by many laboratories will also broaden. So, be prepared, instead, for a larger workload!

\section{Acknowledgments}

The authors wish to thank Soma Mohammed from the Westmead laboratory for technical assistance, and namely testing of the new anticoagulants in various assays, as partly shown in this report.

\section{Potential conflict of interest}

None declared.
Ratio (INR): Time to think outside the box? Clin Chem Lab Med 2010;48:1079-90.

8. Lippi G, Favaloro EJ. Activated partial thromboplastin time: new tricks for an old dogma. Semin Thromb Hemost 2008;34:604-11.

9. Favaloro EJ. Laboratory testing in disseminated intravascular coagulation. Semin Thromb Hemost 2010;36:458-67.

10. Favaloro EJ, Funk (Adcock) DM, Lippi G. Preanalytical variables in coagulation testing associated to diagnostic errors in hemostasis. Lab Medicine 2012;43:54-60.

11. Cuker A. Unfractionated heparin for the treatment of venous thromboembolism: best practices and areas of uncertainty. Semin Thromb Hemost 2012;38:593-9.

12. Lassila R, Antovic JP, Armstrong E, Baghaei F, DalsgaardNielsen J, Hillarp A, et al. Practical viewpoints on the diagnosis and management of heparin-induced thrombocytopenia. Semin Thromb Hemost 2011;37:328-36.

13. Linkins LA, Warkentin TE. Heparin-induced thrombocytopenia: real-world issues. Semin Thromb Hemost 2011;37:653-63. 
14. Cuker A. Current and emerging therapeutics for heparin-induced thrombocytopenia. Semin Thromb Hemost 2012;38:31-7.

15. Prechel M, Walenga JM. Heparin-Induced Thrombocytopenia: An Update. Semin Thromb Hemost 2012;38:483-96.

16. Les I, Ruiz-Irastorza G, Khamashta MA. Intensity and Duration of Anticoagulation Therapy in Antiphospholipid Syndrome. Semin Thromb Hemost 2012;38:339-47.

17. Levi M. Antithrombotic management of atrial fibrillation. Semin Thromb Hemost 2009;35:525-6.

18. Lippi G, Franchini M, Favaloro EJ. Pharmacogenetics of vitamin K antagonists: useful or hype? Clin Chem Lab Med 2009;47:503-15.

19. Božina N. The pharmacogenetics of warfarin in clinical practice. Biochem Med 2010;20:33-44.

20. Budnitz DS, Shehab N, Kegler SR, Richards CL. Medication use leading to emergency department visits for adverse drug events in older adults. Ann Intern Med 2007; 147:755-65.

21. Favaloro EJ, Bonar R, Sioufi J, Wheeler M, Low J, Aboud $M$, et al (on behalf of the RCPA QAP in Haematology). An international survey of current practice in the laboratory assessment of anticoagulant therapy with heparin. Pathology 2005;37:234-8.

22. Walenga JM, Jackson CM, Kessler CM. Low molecular weight heparins differ substantially: impact on developing biosimilar drugs. Semin Thromb Hemost 2011;37:322-7.

23. Favaloro EJ, Bonar R, Aboud M, Low J, Sioufi J, Wheeler $M$, et al (on behalf of the RCPA QAP in Haematology). How useful is the monitoring of (low molecular weight) heparin therapy by anti-Xa assay? The laboratory perspective. Lab Hematol 2005; 11:157-62.

24. Samama MM, Guinet C. Review: Laboratory assessment of new anticoagulants. Clin Chem Lab Med 2011;49:761-72.

25. Ansell J. Warfarin versus new agents: interpreting the data. Hematology Am Soc Hematol Educ Program 2010;2010:221-8.

26. Levy JH, Key NS, Azran MS. Novel oral anticoagulants: implications in the perioperative setting. Anesthesiology 2010;113:726-45.

27. Garcia D, Libby E, Crowther MA. The new oral anticoagulants. Blood 2010;115:15-20.

28. Favaloro EJ, Lippi G. Laboratory testing and/or monitoring of the new oral anticoagulants/antithrombotics: For and against? Clin Chem Lab Med 2011;49:755-7.

29. Harenberg J, Giese C, Marx S, Krämer R. Determination of dabigatran in human plasma samples. Semin Thromb Hemost 2012;38:16-22.

30. Lindahl TL, Baghaei F, Blixter IF, Gustafsson KM, Stigendal L, Sten-Linder M, et al; Expert Group on Coagulation of the External Quality Assurance in Laboratory Medicine in Sweden. Effects of the oral, direct thrombin inhibitor dabigatran on five common coagulation assays. Thromb Haemost 2011;105: 371-8.

31. van Ryn J, Stangier J, Haertter S, Liesenfeld KH, Wienen $W$, Feuring M, Clemens A. Dabigatran etexilate--a novel, reversible, oral direct thrombin inhibitor: interpretation of coagulation assays and reversal of anticoagulant activity. Thromb Haemost 2010;103:1116-27.
32. Douxfils J, Mullier F, Robert S, Chatelain C, Chatelain $B$, Dogné JM. Impact of dabigatran on a large panel of routine or specific coagulation assays. Laboratory recommendations for monitoring of dabigatran etexilate. Thromb Haemost 2012;107:985-97.

33. Stangier J, Feuring M. Using the HEMOCLOT direct thrombin inhibitor assay to determine plasma concentrations of dabigatran. Blood Coagul Fibrinolysis 2012;23:138-43.

34. Nowak G. The ecarin clotting time, a universal method to quantify direct thrombin inhibitors. Pathophysiol Haemost Thromb $2003 \mathrm{Jul}$-2004 Aug;33:173-83.

35. Samama MM, Martinoli J-L, LeFlem L, Guinet C, Plu-Bureau $G$, Depasse F, Perzborn E. Assessment of laboratory assays to measure rivaroxaban - an oral, direct factor Xa inhibitor. Thromb Haemost 2010;103:815-25.

36. Harenberg J, Erdle S, Marx S, Krämer R. Determination of rivaroxaban in human plasma samples. Semin Thromb Hemost 2012;38:178-84.

37. Hillarp A, Baghaei F, Fagerberg Blixter I, Gustafsson KM, Stigendal L, Sten-Linder M, et al. Effects of the oral, direct factor Xa inhibitor rivaroxaban on commonly used coagulation assays. J Thromb Haemost 2011;9:133-9.

38. Gatt A, van Veen J, Woolley AM, Kitchen S, Cooper P, Makris $M$. Thrombin generation assays are superior to traditional tests in assessing anticoagulation reversal in vitro. Thromb Haemost 2008;100:350-5.

39. Favaloro EJ, Wong R. Laboratory testing for the Antiphospholipid Syndrome: making sense of antiphospholipid antibody assays. Clin Chem Lab Med 2011;49:447-61.

40. Kershaw G, Suresh S, Orellana D, Nguy YM. Laboratory Identification of Lupus Anticoagulants. Semin Thromb Hemost 2012;38:375-84.

41. Salmela B, Joutsi-Korhonen L, Armstrong E, Lassila R. Active online assessment of patients using new oral anticoagulants: bleeding risk, compliance, and coagulation analysis. Semin Thromb Hemost 2012;38:23-30.

42. Schulman S, Majeed A. The oral thrombin inhibitor dabigatran: strengths and weaknesses. Semin Thromb Hemost 2012;38:7-15.

43. Franchini $M$, Mannucci $P M$. Thrombin and cancer: from molecular basis to therapeutic implications. Semin Thromb Hemost 2012;38:95-101.

44. Mina A, Favaloro EJ, Mohammed S, Koutts J. A laboratory evaluation into the short activated partial thromboplastin time. Blood Coagul Fibrinolysis 2010;21:152-7.

45. Lippi G, Salvagno GL, Ippolito L, Franchini M, Favaloro EJ. Shortened activated partial thromboplastin time: causes and management. Blood Coagul Fibrinolysis 2010;21:459-63.

46. Bonar R, Favaloro EJ, Adcock DM. Quality in coagulation and haemostasis testing. Biochem Med 2010;20:184-99.

47. Favaloro EJ, Lippi G. Laboratory reporting of hemostasis assays: the final post-analytical opportunity to reduce errors of clinical diagnosis in hemostasis? Clin Chem Lab Med 2010;48:309-21.

48. Tripodi A, Di lorio G, Lippi G, Testa S, Manotti C. Position paper on laboratory testing for patients taking new oral anticoagulants. Consensus document of FCSA, SIMeL, SIBioC and CISMEL. Clin Chem Lab Med, DOI: 10.1515/ cclm-2012-0327, July 2012. 